\title{
Aspecto ecocardiográfico del doble orificio de la válvula mitral
}

\author{
Julián Vega ${ }^{1}$, Luigi Gabrielli ${ }^{1}{ }^{2}$, Paul McNab ${ }^{1}$, Manuel Salinas ${ }^{1}$, Rodrigo Fernández ${ }^{1}$, \\ Matías Macedo ${ }^{1}$, Samuel Córdova ${ }^{1}$. \\ 1. División de Enfermedades Cardiovasculares. Escuela de Medicina. Pontificia Universidad Católica de Chile. Santiago, Chile. \\ 2. Advanced Center for Chronic Diseases (ACCDiS), Escuela de Medicina. Pontificia Universidad Católica de Chile. Santiago, Chile.
}

El doble orificio de la válvula mitral (DOVM) descrito en $1876^{1}$ es una cardiopatía congénita inhabitual ${ }^{2}$, raramente se presenta aislado y frecuentemente se ve asociado a otras cardiopatías congénitas. Existen varias clasificaciones anatómicas, siendo menos prevalente la presentación de dos orificios simétricos divididos completamente por un puente fibroso $(\mathrm{PF})$, como la imagen aquí presentada, correspondiente a una ecocardiografía de superficie de una paciente de 31 años portadora de una tetralogía de Fallot corregida en la infancia. En al panel A se observa un eje corto a nivel de la válvula mitral en diástole, evidenciando dos orificios de similar tamaño (asteriscos amarillos), que corresponde al DOVM tipo central o también denominado balanceado, cada uno conectado a un músculo papilar (panel
D). Los paneles centrales B y E muestran vistas en 3D, el panel B corresponde a una vista ventricular eje corto que evidencia la simetría de ambos orificios y el panel $\mathrm{E}$ a una vista auricular eje corto donde se aprecia el puente fibroso (PF) completo. El panel C demuestra al Doppler color una válvula normofuncionante con flujo diastólico a través de ambos orificios. El Panel F corresponde a una reconstrucción multiplanar (MPR) obtenida de un zoom 3D simulando la orientación anatómica de la válvula en diástole, dando un aspecto en "gaviota" o en "V" invertida. En conclusión estas imágenes permiten familiarizarnos con el aspecto ecocardiográfico de esta singular patología.

Video disponible en http://www.ecocardio.cl/dovm. html. 


\section{Double orifice mitral valve echocardiographic aspect}

Double orifice mitral valve (DOMV) first reported in 1876 , is a rare congenital anomaly, which can present isolated or associated with other congenital heart defects. Various anatomical classifications exist, being the less frequent the existence of two symmetrical orifices divided by a fibrous bridge (balanced type) as the image here displayed, that belongs to a 31 years-old female with a tetralogy of Fallot corrected by surgery in his childhood. Finally, the pictures here depicted acquaint us with the echocardiographic hallmarks of DOMV.

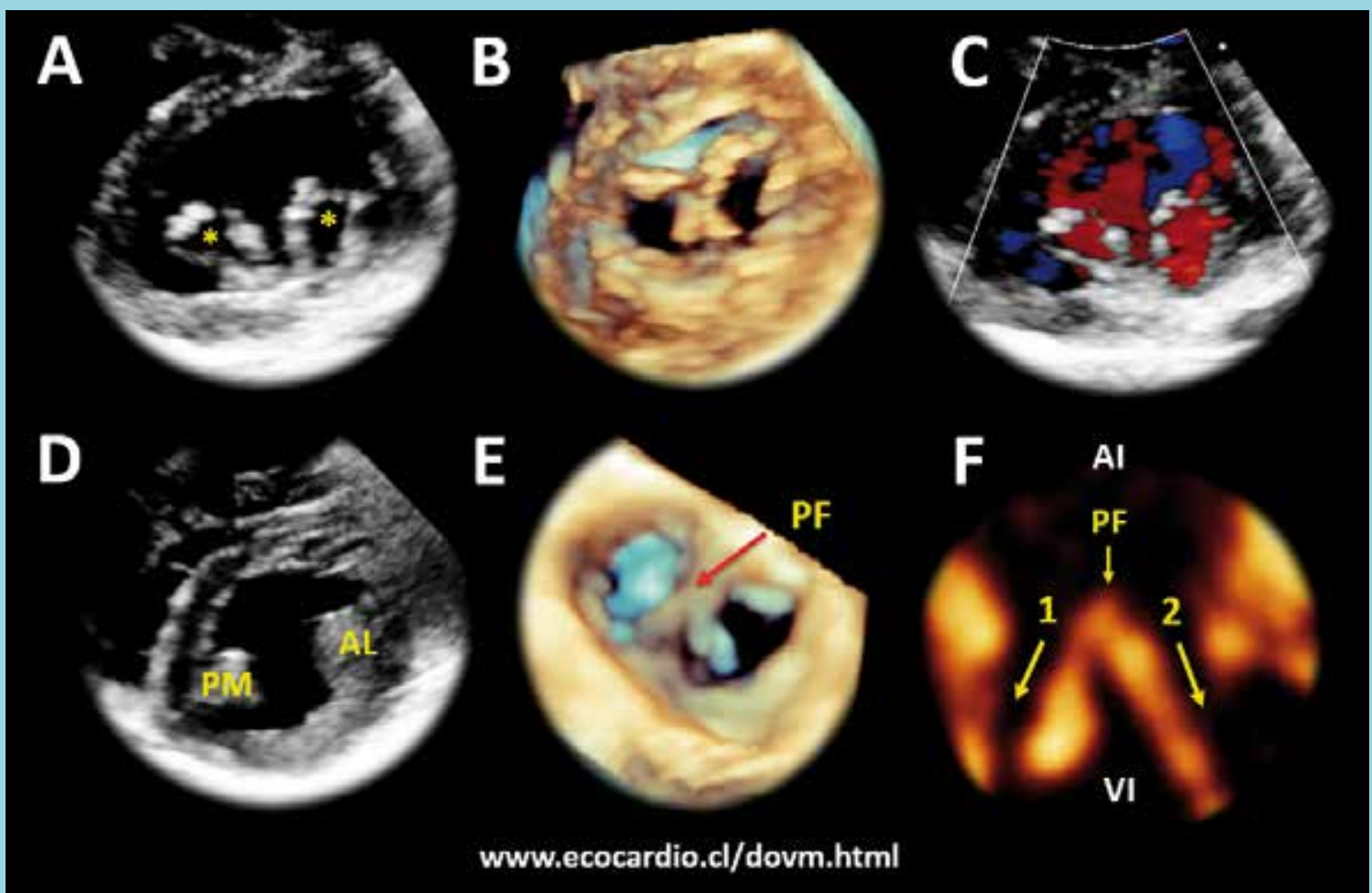

1: Orificio uno, 2: Orificio dos. AL: Músculo papilar anterolateral. PF: Puente fibroso. PM: Músculo papilar posteromedial.

\section{Referencias}

1. GREENFIELD WS. Double mitral valve. Trans Pathol Soc. 1876; 27:128-129.

2. LACCETTA G, NAPOLI AM. J Cardiovasc Echogr. 2016; 26: 100-103. 